DOI https://doi.org/10.18551/rjoas.2017-11.39

\title{
WIFE'S STRATEGY IN MAINTAINING THE STABILITY OF RELATIONSHIP WITH HUSBAND THROUGH COMMUNICATION PRIVACY MANAGEMENT THEORY
}

\author{
Norvitasari Yuni*, Antoni, Kriyantono Rachmat \\ Department of Communication, Faculty of Social and Political Sciences, \\ University of Brawijaya, Indonesia \\ ${ }^{*}$ E-mail: phie june@yahoo.com
}

\begin{abstract}
The discussion on interpersonal communication between husband and wife has become a widely interesting issue. Communication between husband and wife in everyday life is important to maintain the stability of the relationship. By that, this study aims to find the wife's strategy in managing its private information and to find the act which violates and does not violate the privacy of the husband to maintain the stability of the relationship. This research uses the interpretive approach with phenomenology method. The subjects of this research are wives from the conventional type of couple located in Malang. The findings indicate that wife as the owner of private information limits the private information so that the access of the husband to such information is not similar in every subject, thereby reducing the potential of conflict and the relationship becomes more stable. The preventive action taken by the wife when violating the privacy of the husband is to confirm the information in order to eliminate potential conflicts that will occur.
\end{abstract}

\section{KEY WORDS}

Communication, privacy, management, conventional type of couple, phenomenology.

Communication in everyday life is a form of interaction between someone and another. In married life, a couple will engage in a marital relationship in which they constantly interact and communicate interpersonally. Interpersonal communication is a form of communication that occurs between people in the form of face to face and in private settings (Littlejohn, 2002). Furthermore, there is a phenomenon in terms of interpersonal communication between husband and wife which is a communication strategy to keep the harmony of the relationship. The study of family communication done by Farbod, Ghamari, and Majd (2014) found that good communication skills in a couple could generate more explicit message thus creating a good understanding. By that, this can improve the quality of the relationship. Furthermore, Petronio (in Berger, 2014) stated that the act of sharing can enhance family relationship by showing closeness, intimacy, and trust.

On the contrary, the research conducted by Afifi et al., (in Berger, 2014) suggested that the decision to split a message or information on family members can reduce the quality of the relationship especially when the information potentially gives negative effects to the family. Along with the advancement of information technology, other researchers in the field of Communication Privacy Management (CPM) have conducted a development which discussed private communication in the use of social media (Trepte, 2015; Suh \& Hargittai, 2015; Ukung, 2013). Most CPM research on social media deals with how the owners of social media protect their private information while interacting with other social media users. Besides that, Petronio (2000) explained that gender gives influence to the level of someone's openness. The results of Lermer et al., (2016) give an influence on the direction of this research. The findings from Lermer, Streicher, Sachs, Raue, and Frey (2016) proved that women choose to take less risk than men. The finding indicates that there is an influence on the communication behavior made by the wife to the husband. The author also found that married couples are not always open to one another. Not all topics or issues are communicated openly by the couple. In fact, lying also committed by the couple in conveying information. Related to the act of lying, Burgoon \& Buller stated that in some interpersonal communication activity, lying can be used as a way to keep each other's feelings (Griffin, 
2014). This is actually the gap found by the author that becomes the underlying background to do a research in concern to strategies undertaken by the wife to keep the harmony of the relationship with the husband.

Based on the theme of the research, Communication Privacy Management Theory is considered as the most suitable theory for the study analysis. The Theory of Communication Privacy Management (CPM) proposed by Sandra Petronio points out that CPM is a map to describe how a person delivers its private information (West \& Turner, 2003). This theory talks about the limits of privacy in directing the information but remain unknown to others. In more detail, CPM is able to describe the way a person organizes private information for him/herself and in concern to other parties which they are deemed to meet the criteria to access the private information (Afifi \& Afifi, 2009).

The research performed on some wives from the conventional type of couple. According to Fitzpatrick (in Berger, 2014), the characteristics of the conventional or traditional type of couples deeply respect the stability of the relationship and follow cultural rules as well as the role of gender. They are the type of couple who are dependent on each other, physically bonded, and spend a lot of time together. Couples of this type are very expressive and pay more attention to issues that lead to conflict. The reason the author chose this type of couples as research subjects is because they have a good quality of family relationship as illustrated by Petronio in terms of closeness, intimacy, and trust. In addition, they also have a way of communication as described by Farbod, Ghamari, and Majd (2014) which is explicit and open. Within the conventional type of couples, the experience of the wives in communicating with the husband becomes the reason of the author to conduct more research focusing on how the wives arrange private information to the husband and the actions that violate or not violate the privacy of the husband in order to maintain the stability of the relationship.

\section{LITERATURE REVIEW}

Communication Privacy Management Theory. According to Sandra Petronio in Afifi \& Afifi (2009) Communication Privacy Management Theory is a framework that is very useful to provide an understanding that confidentiality requires us to see that: 1) privacy and confidentiality works as a pressure, 2) simultaneously, the need for privacy and access (openness) will have an effect on someone's decision-making process whether to keep it as secret or confess. The dialectic between pressures to push and pull has caused a person to open its private issues or to keep things in order so that others will not know its private information. Frequently, a person becomes open by considering the risk-benefit factors because of some motivation to achieve goals or some cultural expectations. Furthermore, the decision to become open provides the potential in influencing the confidant assessment whether to inform or to keep private information to others (Petronio, 2000). Through the use of boundary metaphors, CPM describes how someone manages its privacy privately and its correlation to confidant (Petronio, 2000).

In the process of managing one's privacy and making choices about the flow of private information, CPM theory recommends six principles: 1) people believe that they have private information (owner), 2) because they believe that they have private information, they feel to have the right to set their private information, 3) to regulate the flow of private information, people use the rules of privacy based on the criteria they considered important, 4) once they open their private information, the authenticity of the information is changed into a joint ownership of confidant, 5) ideally, once the information is shared, a collective negotiation to formulate the rules of privacy and approval by both sides will occur, 6) because someone is not always consistent, effective, or active in the collective negotiation, there is a possibility of "boundary turbulence" which means a reduction in the way of co-owner to control and regulate the flow of information to third parties (Afifi \& Afifi, 2009).

According to the theory of CBM (Boundary Communication Management), how individuals organize private information depend on the structural limitations and management systems. Structural limitations as private information controller stand alone because they 
realize once they share the information, they will become prone because the confidant can divulge their information to other parties. There are four important points of structural limitations, such as a) boundary ownership, b) boundary control, c) the level of boundary openness, and d) boundary permeability.

Boundary Ownership. Once an information is shared with other parties in an interaction, means that the information belongs to both parties. Each party has the obligation to organize such information (Petronio in Mattson and Brann, 2002). The limits of communication not only cover the confidentiality of information but also the arrangements in sharing or closing the information to others.

Boundary Control. Limitations are based on rules that govern the pressure between privacy and openness. The rules will govern the sharing of classified information into categories, ranging from loose to tight (Petronio in Mattson \& Brann, 2002). Within that scale, the control over information is varied. This considerably depends on whom the information is opened, on the relationship between the communicator and the communicant, and on the sensitivity of the information being discussed.

Levels of Boundary Openness. Levels of boundary openness mean the accessibility degree of private information allowed to be exceeded. The degree of openness, as well as boundary control, is categorized on a scale ranging from very open to completely closed (Mattson \& Brann, 2002). It is often found that there are similarities between the boundary control with levels of boundary openness.

Boundary Permeability. Based on the theory of CPM/CBM, more sensitive information will be guarded by more boundaries. This also leads to stronger sanctions if there is a leak of information. On the contrary, the lower the sensitivity of the information, the limitation will be easier to penetrate. This, of course, will result in weaker sanctions (Petronio, 2000).

Types of Couple According to Fitzpatrick. There are three types of couples formulated by Fitzpatrick such as traditional/conventional type, independent type, and separate type (Berger, 2014). The following sections are the characteristics of each type.

Traditional/conventional is a type of couples who deeply appreciate the stability of the relationship and adhere to cultural and gender roles. Couples of this type are interdependent to each other. They are physically bonded because they give priority to togetherness and spend a lot of time together. They also very expressive and pay more attention to the issues of conflict.

Independent is the type of couples that is contrary to the traditional pair. This type believes that a relationship does not have to inflame individual freedom and does not require novelty. They are closely related emotionally even though they are physically separated and have little time to gather together. This kind of couple is very expressive, supportive, and open to conflict.

Separate is the type of couple that has an unclear ideology in the relationship. It often applies the traditional ideology in the relationship but also apply the ideology of individual freedom in it. Sometimes they show a conventional relationship when dealing with the public, but when it is in the private sphere, they will act in an independent manner.

\section{METHODS OF RESEARCH}

This study is a qualitative research with an interpretive paradigm or approach. The method used is phenomenology, which Hegel in Moustakas (1994) stated that phenomenology is a knowledge emerged in consciousness to be seen, felt, and known by one's consciousness and experience. The purpose of this phenomenological method is to find the essence of an experience and to provide a systematic and disciplined methodology in order to find the authenticity of a knowledge (Husserl in Moustakas, 1994).

By using phenomenology, the author will focus on how the limit of privacy within marital interactions are built and controlled. This study will use the theory of Communication Privacy Management (Petronio, 2000) as the point of view to analyze research problems. The steps undertaken by the author in this research are: 1) find the topic and problems, 2) conduct a literature review towards related studies, 3) prepare questions for interview, 4) perform deep 
interviews and record the whole conversation during the interview, 5) do the data analysis by using phenomenology technique.

This research was conducted in Malang with three wives from the traditional type of couple as informants. These informants are selected because each informant represents different family background. Informant I represents a family with different beliefs, informant II represents a family with busy working hours, and informant III represents a family with different tribe and ethnicity. Furthermore, in-depth interviews were conducted to obtain necessary information. Further analysis was also done to obtain the results of research.

\section{RESULTS AND DISCUSSION}

Here are the results of the interview that has been done. It is found that in maintaining the stability of the relationship, the wife which owns a number of private information makes an adjustment to limit private information so that the access of the husband to such information is not the same in every subject. Each type of information has its own set of constraints based on the factors that influence it. The main purpose of arranging such information is to avoid conflicts or reduce the potential for conflict so that the couple's relationships become more stable and in harmony.

The information arranged consciously by the wife are a financial topic, wife's past romantic relationship topic, and family relationship topic. The discussion of the financial topic is regulated by using open, semi-open, closed, and lying arrangements. On the other hand, the delivery of wife's past romantic relationship topic is governed by a semi-open setting. It differs as for the submission of family relationship/wife family issues. The message is arranged in the half-open and closed setting. Unconsciously, wives often violate the privacy of their husbands because of the confirmation of information heard through third parties that have not been assured. This happens because of the urge to eliminate the potential conflict with the actual information to obtain clarification of the husband. The encouragement of the wife to immediately know the truth is the influence of the emotional nature of the woman (Lenz in Papalia and Olds, 1998).

The choice of the wives whether or not to find the information deliberately is part of the strategy to maintain the stability of the relationship. A wife who chooses to respect the privacy of her husband by not trying to find out the private information of her husband feels that it is one of the ways to maintain the stability of her relationship.

\section{CONCLUSION AND SUGGESTIONS}

Based on the findings of the research, some propositions which refer to the theory of Communication Privacy Management (CPM) are found:

In general, there are similarities when the wife (conventional type) decided to limit the privacy of certain topics without affected by the background of the husband such as financial topic, past romantic relationship topic and family relationship topic.

This type of wife is open on issues that influenced the lives of the couple, as for an instance, financial problems.

Conventional type of wife prefers to be covered or not fully open to the problems that potentially bother the couple and can trigger conflicts. This is related to the statement of Petronio (2000) in which gender gives an influence to the decision-making of someone whether to share or not to share private information.

Lying is not the main selection of the conventional type of wife to avoid conflict with the husband.

An open attitude towards all the problems in marriage does not guarantee the stability of the relationship.

Suggestions. A couple should carefully consider the topics to be discussed or delivered. They must carefully calculate the potential that will arise when an issue is raised to be discussed. In addition, they should consider certain ways when they convey a sensitive issue so as not to get carried away by emotion in between two sides. 


\section{REFERENCES}

1. Afifi, T. A., and Afifi, W. A. (2009). Uncertainty, Information Management and Disclosure Decisions: Theories and Applications. NY: Routledge.

2. Berger, Charles R. (2014). Interpersonal Communication. Berlin: De Gruyter.

3. Farbod, Elnaz, Ghamari, Mohammad, Majd, Mojtaba Amiri. (2014). Investigating The Effect of Communication Skills Training for Married Women on Couple's Intimacy and Quality of Life. Sage Open, 1-4.

4. Griffin, Em. (2014). A First Look At Communication Theory (9th ed). NY: McGraw Hill.

5. Lermer, Eva, Streicher, Bernhard, Sachs, Rainer, Raue, Martina, \& Frey, Dieter. (2016). The Effect of Abstract and Concrete Thinking on Risk-Taking Behavior in Women and Men. Sage Open, 1-4.

6. Littlejohn, Stephen W. (2002). Theories of Human Communication (5th ed). NY: Wardsworth.

7. Mattson, Marifran and Brann, Maria. (2002). Managed Care And The Paradox Of Patient Confidentiality: A Case Study Analysis From A Communication Boundary Management Perspective. Communication Studies, 53(4), 337-357. Diakses dari Proquest Research Library: Social Sciences.

8. Moustakas, Clark E. (1994). Phenomenological Research Methods. Thousands Oaks, California: Sage Publications.

9. Papalia, Diane E., and Olds, Sally Wendkos. (1998). Human Development (2nd ed). NY: McGraw-Hill.

10. Petronio, S. (2000). The Boundaries of Privacy: Praxis Of Everyday Life. Mahwah, NJ: Lawrence Erlbaum.

11. Suh, Jennifer Jiyoung \& Hargittai, Eszter. (2015). Privacy Management On Facebook: Do Device Type And Location Of Posting Matter?. Social Media Society, 1-11.

12. Trepte, Sabine. (2015). Social Media, Privacy, And Self-Disclosure: The Turbulence Caused By Social Media's Affordances. Social Media Society, 1-2.

13. Ukung, Anneke Mathilda. (2013). Communication Privacy Management Penderita HIV di Media Facebook. Jurnal E-Komunikasi, 1(3), 70-79.

14. West, Richard \& Turner, Lynn H. (2003). Introducing Communication Theory (2nd ed). NY: McGraw Hill. 